\title{
ГОСУДАРСТВЕННАЯ ПОЛИТИКА АКТИВНОГО ДОЛГОЛЕТИЯ: О ЧЕМ СВИДЕТЕЛЬСТВУЕТ МИРОВОЙ оПыт
}

\author{
МАРИНА КОЛОСНИЦЫНА, НАТАЛЬЯ ХОРКИНА
}

\begin{abstract}
Демографическое старение - тенденщия, характерная сегодня для большинства стран мира, в том числе и для России. Число и доля пожильх людей растет, и важным направлением соииальной политики становится создание возможностей для здорового и активного долголетия. Приняты и действуют международные документы по проблемам старения, во многих странах существуют специиальные государственные органы, ответственные за политику в отношении пожильх, реализуются национальные стратегии, активно поддерживаются инициативы организаџий, занимающихся поддержкой лии старшего возраста. В то же время государственная политика активного долголетия в России пока не имеет четко выраженного и целенаправленного характера. В статье анализируется зарубежный опыт государственной поддержки пожильх людей, приводятся оценки эффективности используемых механизмов политики активного долголетия в развитых странах, вылвляются наиболее результативные меры, обсуждаются возможности применения зарубежного опыта в нашей стране. За основу анализа взят опыт стран, занимаюших ведущие позищии в рейтинге стран мира по качеству жизни пожилых людей, уделяющих повышенное внимание проблемам лии старшего возраста. Эти страны успешно реализуют разнообразные механизмы в области активного долголетия на протяжении нескольких лет как на общегосударственном, так и на территориальном уровне, осуществляют мониторинг и оценку эффективности используемых механизмов политики активного долголетия. В соответствии $c$ конщепџией активного старения Всемирной организаџии здравоохранения анализ проводился для таких компонентов активного долголетия, как физическая, трудовая и сочиальная активность. Проведенный анализ действующих в мировой практике мер позволил выявить наиболее эффективные инструменты государственной политики активного долголетия (финансовые, образовательные, организаџионные, информационные) и сформулировать рекомендации для разработки национальной политики по активизации образа жизни пожильх россиян и созданию достойных условий для успешного старения в России.
\end{abstract}

Ключевые слова: активное долголетие, пожилье люди, физическая активность, трудовая активность, социальная активность, государственная соџиальная политика.

\section{ПОСТАНОВКА ПРОБЛЕМЫ}

Демографическое старение - важнейшая тенденция в современном мире. По данным Росстата, доля россиян пенсионного возраста превысила сегодня 24\% и, согласно имеющимся прогнозам, будет расти и дальше, приближаясь к 28\% в 2030 г. [Вишневский, Андреев 2014; Демографический ежегодник России 2015]. Политика активного долголетия выступает на первый план во всех развитых странах как реакция на демографическое старение, нехватку трудовых ресурсов, кризис пенсионных систем.

\footnotetext{
МАРИНА ГРИГОРЬЕВНА КОЛОСНИЦЫНА (mkolosnitsyna@hse.ru), НАЦИОНАЛЬНЫЙ ИССЛЕДОВАТЕЛЬСКИЙ УНИВЕРСИТЕТ «ВЫСШАЯ ШКОЛА ЭКОНОМИКИ», РОССИЯ.

НАТАЛЬЯ АЛЕКСЕЕВНА ХОРКИНА, НАЦИОНАЛЬНЫЙ ИССЛЕДОВАТЕЛЬСКИЙ УНИВЕРСИТЕТ ВЫСШАЯ ШКОЛА экономики», Россия.
}

ИССЛЕДОВАНИЕ ОСУЩЕСТВЛЕНО В РАМКАХ ПРОЕКТА ПРОГРАММЫ ФУНДАМЕНТАЛЬНЫХ ИССЛЕДОВАНИЙ НАЦИОНАЛЬНОГО ИССЛЕДОВАТЕЛЬСКОГО УНИВЕРСИТЕТА «ВЫСШАЯ ШКОЛА ЭКОНОМИКИ» «СОЦИАЛЬНАЯ ПОДДЕРЖКА НАСЕЛЕНИЯ: ЦЕЛЕВЫЕ ГРУППЫ И ПРИОРИТЕТЫ» В 2016 Г.

СТАТЬЯ ПОСТУПИЛА В РЕДАКЦИЮ В ОКТЯБРЕ 2016 Г. 
В последние годы и в России растет внимание правительства к проблемам пожилых людей. Основные положения государственной политики в отношении пожилых россиян отражены в ряде федеральных законов ${ }^{1}$. Приняты основополагающие документы в области социальной поддержки лиц старшего возраста. В утвержденной в 2014 г. Государственной программе «Социальная поддержка граждан» среди приоритетных задач выделено выполнение обязательств государства по социальной поддержке пожилых людей². Развитие системы социальной поддержки лиц старшего возраста на среднесрочную перспективу обсуждалось в августе 2014 г. на заседании Государственного совета Российской Федерации «О развитии системы социальной защиты граждан пожилого возраста» ${ }^{3}$. На необходимость корректировки действующих мер поддержки социально незащищенных слоев населения в условиях структурного кризиса российской экономики указали участники прошедшего в январе 2016 г. Гайдаровского форума ${ }^{4}$. Важным документом, заложившим ориентиры современной государственной политики в области активного долголетия и улучшения качества жизни пожилых россиян, стала принятая в феврале 2016 г. «Стратегия действий в интересах граждан старшего поколения в Российской Федерации до 2025 года» 5 . Повышенный интерес к отдельным аспектам старения населения как экономической проблеме наблюдается в последние годы и со стороны экспертного сообщества [Гурвич, Сонина 2012; Малева, Юдаева 2013; Синявская 2010; Сонина, Колосницына 2015].

Однако, как отмечают эксперты, несмотря на значительное число нормативноправовых документов, затрагивающих вопросы социальной поддержки лиц старшего возраста, действующая социальная политика в отношении пожилых граждан России пока не имеет четко выраженного и целенаправленного характера [Сабитова и др. 2011; Румянцева 2013]. России все еще не хватает комплексного подхода к проблеме старения населения с учетом меняющихся потребностей пожилого населения и возможностей, связанных с этими изменениями.

В то же время в развитых странах реализация программ активного долголетия приобрела комплексный характер, они успешно осуществляются на протяжении уже многих лет, и, что особенно важно, выработаны механизмы оценки эффективности действующих мер, на основании которых проводится их корректировка. Поэтому цель настоящей работы - проанализировать зарубежные исследования, посвященные эффективности отдельных мероприятий социальной политики активного долголетия,

\footnotetext{
${ }^{1}$ Федеральные законы №1032-1 от 19 апреля 1991 г. «О занятости населения в Российской Федерации»; №181-Ф3 от 24 ноября 1995 г. «О социальной защите инвалидов в Российской Федерации»; №5-Ф3 от 12 января 1995 г. «О ветеранах».।; №82-Ф3 от 19 мая 1995 г. «Об общественных объединениях»; №135-Ф3 от 11 августа 1995 г. «О благотворительной деятельности и благотворительных организациях»; №442-Ф3 от 28 декабря 2014 г. «Об основах социального обслуживания граждан в Российской Федерации» и др.

2 Постановление Правительства РФ №296 от 15 апреля 2014 г. «Об утверждении государственной программы Российской Федерации «Социальная поддержка граждан».

${ }^{3}$ http://www.kremlin.ru/acts/assignments/orders/46594

${ }^{4}$ http://www.gaidarforum.ru/news/view/novosti11/Naselenie-otvetilo-na-krizis-smenoj-struktury-potrebleniya/

${ }^{5}$ Распоряжение Правительства РФ №164-р от 5 февраля 2016 г. «Об утверждении Стратегии действий в интересах граждан старшего поколения в Российской Федерации до 2025 года».
} 
реализуемых в разных странах, и выявить наиболее предпочтительные инструменты, которые могли бы применяться и в России.

В статье рассмотрен опыт стран, уделяющих повышенное внимание проблемам пожилых людей, успешно реализующих разнообразные механизмы в области активного долголетия на протяжении длительного периода, а также осуществляющих оценку эффективности используемых мер. Кроме того, большинство стран, опыт которых анализируется в статье, занимают лидирующие позиции в рейтинге стран мира по качеству жизни пожилых людей, составленном международной благотворительной организацией HelpAge International при поддержке ООН [HelpAge International 2015].

Анализ эффективности мер государственной поддержки пожилых проводится применительно к таким компонентам активного долголетия, как физическая, трудовая $и$ социальная активность. Такой подход к трактовке активного долголетия соответствует концепции активного старения Всемирной организации здравоохранения (ВО3): «активное долголетие - процесс оптимизации возможностей в плане здоровья, участия и безопасности в целях повышения качества жизни по мере старения людей» [WHO 2002: 12]. Сегодня он широко используется учеными, занимающимися вопросами старения [Chansarn 2012; Zaidi et al. 2013; Zasimova, Sheluntcova 2014]. Трудовая активность выделяется среди прочих видов социальной активности именно потому, что обеспечивает пожилому человеку самостоятельный доход как ключевой элемент безопасности. Физическая активность в пожилом возрасте - необходимая основа здоровья.

Имеющиеся оценки индекса активного долголетия, выполненные на основе российских данных, свидетельствуют о том, что минимум $41,5 \%$ россиян в возрасте от 55 лет и старше не соответствуют основным критериям активного долголетия, обозначенным в определении ВО3 [Zasimova, Sheluntcova 2014]. Данное обстоятельство является важным аргументом в пользу необходимости разработки и внедрения комплексного подхода к проблеме старения российского населения с учетом наиболее значимых для России факторов активного долголетия.

\section{СТИМУЛИРОВАНИЕ ФИЗИЧЕСКОЙ АКТИВНОСТИ ПОЖИЛЫХ ЛЮДЕЙ}

Достаточный уровень физической активности отмечается экспертами в качестве одного из ключевых факторов, влияющих на качество жизни лиц старшего возраста и создающих неоспоримые выгоды для страны в целом [BО3 2010]. Разнообразные программы и инструменты государственной политики, позволяющие повысить физическую активность пожилого населения, в последние десятилетия стали весьма популярными во многих странах.

\section{Национальные программы физической активности}

Мероприятия, стимулирующие двигательную активность пожилых людей, как правило, являются частью комплексной национальной программы по пропаганде здорового образа жизни или более узкого национального проекта, пропагандирующего активный образ жизни. В отдельных странах подобные мероприятия стали частью национальных кампаний 
по активному долголетию (Великобритания, Канада) [A literature review... 2011]. Постепенно расширяется круг стран, реализующих государственные программы по активизации образа жизни пожилых (Финляндия, Испания, Канада) [Schoppe et al. 2004].

Несмотря на то, что реализация подобных кампаний осуществляется недавно, уже начали появляться первые оценки предпринимаемых национальными правительствами действий. К примеру, достаточно высокой результативностью характеризуется программа физической активности для жителей Финляндии преклонного возраста, стартовавшая в 2005 г. при финансовой поддержке правительства. Оценка результатов программы, реализованной в 13 пилотных регионах страны на протяжении четырех лет, выявила трехкратное увеличение числа пожилых финнов, регулярно посещающих групповые занятия физкультурой [Karvinen et al. 2014].

В систематическом обзоре государственных программ физической активности девяти стран к числу общих принципов успешного осуществления подобных правительственных инициатив авторы, в частности, отнесли основанное на взаимном уважении и доверии широкое взаимодействие большого числа заинтересованных сторон, четкую организационную структуру, а также распространение и обмен информацией между всеми участниками [Schoppe et al. 2004].

\section{Информационнье руководства}

С целью активизации образа жизни пожилых людей в ряде зарубежных стран разработаны специальные информационные руководства по физической активности для лиц старшего возраста и организаторов соответствующих программ. К числу важных документов международного уровня относятся «Глобальные рекомендации по физической активности для здоровья» [ВОЗ 2010], включающие раздел о стимулировании физической активности лиц в возрасте 65 лет и старше. Данные материалы содержат как информацию о рекомендуемых уровнях и типах физической активности, так и возможные инструменты по стимулированию двигательной активности.

\section{Грантовая поддержка мероприятий по стимулированию физической активности пожилых}

Одним из результативных примеров подобной инициативы является программа грантов по продвижению физической активности среди пожилых жителей Ирландии, начатая в 2001 г. Программа была поддержана государственной организацией Национальный совет по спорту и благотворительной организацией «Возраст и возможности». За четырнадцать лет ее реализации более 9000 организаций по всей стране получили финансирование в общем объеме более 4,2 млн евро. Гранты в размере от 250 до 1500 евро, как правило, направлялись на закупку специального оборудования, обустройство спортивных площадок, а также на инициирование новых подобных проектов [Go For Life... 2014].

Другая успешная программа - региональная программа по стимулированию физической активности пожилого населения Калифорнии (США), стартовавшая в 2001 г. по инициативе местных органов власти и спонсируемая благотворительной организацией Фондом Р.В. Джонсона. За период реализации программы участниками мероприятий, 
организованных грантополучателями, стали более 12,5 тыс. пожилых американцев, создано более 300 групп пожилых людей, занимающихся физкультурой с инструктором, организовано 36 специальных семинаров, на которых прошли обучение свыше 400 инструкторов [California Agencies... 2007].

\section{Информационные кампании в средствах массовой информации (СМИ)}

СМИ задействуют организаторы практически любой кампании по пропаганде активного образа жизни, однако пожилая аудитория имеет ряд особенностей. Так, исследователи отмечают слабый мотивационный эффект включения в информационные сообщения сведений о пользе активного образа жизни для здоровья и предлагают в рекламных кампаниях в СМИ основное внимание уделять разъяснению психоэмоциональных и социальных выгод от физической активности [Nicholson 2004]. Необходимо учитывать и тот факт, что пожилые люди настороженно воспринимают спортивную терминологию, поскольку она ассоциируется с рисковыми занятиями, травмами и тяжелой работой [Nicholson 2004].

Другой отличительной чертой информационных кампаний по пропаганде активного образа жизни среди пожилых является их более высокая чувствительность к материалам, размещенным на телевидении и радио, по сравнению с материалами, опубликованными в печатных изданиях [Finch 1997]. Кроме того, в ходе опроса пожилых британцев было установлено, что пожилые люди предпочли бы в роликах, пропагандирующих двигательную активность, видеть не спортсменов или молодежь, а физически активных сверстников [Finch 1997].

\section{Консультации медицинских работников}

К числу важных мер, способных активизировать образ жизни пенсионеров, эксперты относят консультации медицинских работников [Nicholson 2004]. К примеру, одним из главных факторов, определивших решение пожилых британцев участвовать в программе физической активности, стало доверительное отношение к рекомендациям, полученным от врача [Stathi et al. 2003]. Результаты обширного исследования образа жизни более 7000 пожилых жителей Австралии позволили к числу ключевых факторов, побудивших пожилых австралийцев начать заниматься физкультурой в домашних условиях, отнести 23-минутные консультации врачей, раскрывающие преимущества физической активности в зрелом возрасте и способы увеличения двигательной активности дома [Bull, Jamrozik 1998]. По истечении 6 месяцев наблюдений учеными были установлены значимые отличия в уровне физической активности у тех, кто имел предварительные беседы с медработником, по сравнению с контрольной группой пациентов [Bull, Jamrozik 1998]. Авторы другого исследования обнаружили, что консультации врача повышали вероятность начала занятий физкультурой и спортом в 5-6 раз [Hirvensalo et al. 1998].

\section{Групповые пешие прогулки}

Одним из наиболее популярных и распространённых видов двигательной активности среди лиц старшего возраста большинства стран является ходьба [AARP 2007]. К числу успешных 
инициатив такого рода относятся, например, групповые пешие прогулки с шагомером, получившие распространение в большинстве штатов США и осуществляемые при финансовой поддержке местной администрации. Эта инициатива помогла участникам повысить уровень повседневной физической активности, а кроме того, многие из них продолжили самостоятельно заниматься ходьбой и после завершения кампании. Помимо этого, регулярные пешие прогулки стали существенным фактором, побудившим пожилых американцев к занятиям другими видами двигательной активности [AARP 2007]. Пешие прогулки отличаются существенной результативностью, и при этом их проведение не требует значительных затрат.

\section{ГОСУДАРСТВЕННАЯ ПОЛИТИКА, СТИМУЛИРУЮЩАЯ ЗАНЯТОСТЬ пожилых}

Меры государственной политики занятости в отношении пожилых людей важны как для стимулирования экономического роста, так и для благополучия стареющего общества в целом. В самом общем виде их можно разделить на две большие группы: меры, стимулирующие предложение, и меры, увеличивающие спрос на рынке труда.

\section{Меры государственной политики, увеличивающие предложение труда}

\section{Параметры пенсионной системы}

В исследованиях, выполненных на основе анализа микроданных отдельных стран [Gruber, Wise 2004; Schils 2008], а также посвященных сравнительному анализу агрегированных национальных показателей [Burniaux et al. 2003; Duval 2003; Blöndal, Scarpetta 1998], подчёркивается высокая значимость параметров государственной пенсионной системы как важного фактора, влияющего на решение человека о продолжении трудовой карьеры после достижения возраста выхода на пенсию.

\section{Поддержка обучения и переобучения}

Появившиеся в последние годы исследования, посвященные оценке отдачи от обучающих программ для лиц старшего возраста, позволяют судить об их положительном эффекте [Van Horn et al. 2015]. К примеру, американскими учеными были проанализированы заработки пожилых людей на протяжении нескольких лет после окончания программы переобучения [Jacobson et al. 2003]. В итоге было установлено, что дополнительный год обучения приводит к росту доходов в долгосрочной перспективе, в среднем, на 8\% для пожилых мужчин и на 10\% для женщин [Jacobson et al. 2003]. При этом наибольшей отдачей характеризуется дополнительное образование в области технических специальностей и в сфере здравоохранения. Однако, несмотря на достаточную результативность подобных программ, число их участников невелико. Среди причин авторы выделяют недостаточную осведомленность пожилых людей о потенциальных преимуществах подобных программ, а также недостаток информации об их реализации [Jacobson et al. 2003]. 


\section{Информационная поддержка}

На повышение трудовой активности пожилых людей направлена деятельность государственных образовательных учреждений, предоставляющих информацию пожилым о текущих потребностях рынка труда. Можно привести пример программы Системы государственных и технических колледжей Кентукки, а также программы Университета Висконсина, позволяющих пенсионерам в реальном времени определить наиболее востребованные на рынке труда навыки [Ganzglass 2014]. Востребованность этих программ у пожилых людей позволяет предположить, что они способны оказать несомненную пользу лицам пенсионного возраста, желающим продолжить трудовую карьеру [Van Horn et al. 2015].

\section{Изменение условий занятости}

Возможность работать сокращенный рабочий день и наличие гибкого графика работы эксперты относят к ключевым факторам, определяющим решение пожилого человека о продолжении трудовой карьеры после достижения пенсионного возраста [OECD 1999; 2006]. В исследованиях факторов занятости пожилых американцев установлено, что они предпочитают неполную занятость как некий «мостик» между полной занятостью и выходом на пенсию [Friedberg 2007; Ruhm 1990]. Эта тенденция особенно ярко выражена для более образованных работников с высоким уровнем дохода. Кроме того, эксперты подчеркивают, что льготные условия занятости позволяют пожилым людям оставаться в составе рабочей силы на протяжении достаточно длительного периода после достижения пенсионного возраста [OECD 2006].

\section{Меры государственной политики, стимулирующие спрос}

\section{Антидискриминационная политика на рынке труда}

Распространенным явлением как при найме работников, так и в их дальнейшей работе, становятся проявления дискриминации лиц старшего возраста или эйджизма. Антидискриминационные законы приняты сегодня во всех странах ОЭСР. Однако, как отмечают эксперты, преодолеть сложившеюся ситуацию только с их помощью невозможно [OECD 2004]. В качестве примера должного отношения к пожилым работникам может выступать само государство как работодатель, реализуя антидискриминационную политику при найме, обучении и продвижении персонала.

\section{Законодательство о защите занятости}

Нередко законодательство о защите занятости закрепляет штрафы для работодателя или существенные выплаты работникам в случае увольнения пожилых сотрудников. Это означает, что работодателям, по сути, невыгодно нанимать пожилых людей, так как в случае необходимости сокращений персонала их невозможно уволить. Экспертами отмечаются отрицательное воздействие таких мер на занятость и мобильность пожилых работников и необходимость либерализации соответствующих законов [OECD 2006]. В ряде стран уже предприняты определённые действия в этом направлении. К примеру, новое законодательство Нидерландов устанавливает необходимость структурного соответствия состава увольняемых сотрудников составу персонала предприятия. В итоге защита от 
увольнений принимает унифицированную форму в отношении всех возрастных групп работников [OECD 2005b].

\section{Изменение стереотипного отночения}

Анализ зарубежного опыта показал, что даже в странах с относительно высоким уровнем занятости лиц старшего возраста характерны определенные предубеждения нанимателей в отношении пожилых работников. Изменить подобную ситуацию могли бы государства, собирая и распространяя информацию о лучших методах управления персоналом в организациях, уделяющих повышенное внимание стареющей рабочей силе [OECD 2004].

\section{Субсидии или налоговые льготы}

Прямым финансовым стимулом к найму пожилых работников могут стать субсидии или налоговые льготы, позволяющие снизить затраты нанимателя, связанные с наймом работников старших возрастных групп. Так, отмена в 2004 г. в Нидерландах одного из социальных налогов на зарплату работников в возрасте 50 лет и старше привела к снижению расходов работодателя на эту группу сотрудников на 5\% [OECD 2005b]. В Австрии после уменьшения обязательных социальных налогов на зарплату женщин, начиная с 56 лет, и мужчин, начиная с 58 лет, издержки работодателя на рабочую силу снизились на 12\% [OECD 2005a].

\section{СТИМУЛИРОВАНИЕ СОЦИАЛЬНОЙ АКТИВНОСТИ ПЕНСИОНЕРОВ С ПОМОЩЬЮ ИНФОРМАЦИОННО-КОМПЬЮТЕРНЫХ ТЕХНОЛОГИЙ}

Информационно-компьютерные технологии (ИКТ), ресурсы сети Интернет несомненно обладают существенным потенциалом, способным активизировать образ жизни пожилых людей, содействовать их социальной интеграции и более активному вовлечению в общественную и трудовую деятельность.

\section{Информационная поддержкка}

Одним из способов добиться уверенного владения ИКТ пожилыми людьми является обеспечение регулярной внешней поддержки их работы с компьютерными технологиями. Примером успешной реализации подобного подхода на практике выступает британский сайт www.digitalunite.com, разработанный и функционирующий при финансовой поддержке органов государственной власти Великобритании. Основная его задача - в доступной форме разъяснить пожилым людям основные возможности, которые предоставляют ИКТ для повседневного использования. Большая востребованность и популярность этого ресурса у пожилых людей (тысячи пользователей ежегодно) позволяют говорить о достаточной результативности подобного вида информационной поддержки [Independent Age 2011].

Еще один пример - программа CareOnLine, реализованная в графстве Лестершир (Великобритания) при финансовой поддержке местных органов власти [Independent Age 2011]. Ее цель - предоставление информационных услуг для пожилых людей и содействие их компьютерной грамотности. В ходе реализации программы был разработан 
специальный сайт для пожилых людей, нуждающихся в социальной поддержке: www.leicscareonline.org.uk/index/about_careonline.htm. В результате пенсионеры получили возможность онлайн-общения как со специалистами местных социальных служб, так и со сверстниками. Оценка результатов программы по итогам 2003 г. показала, что 97\% пользователей отметили полезность сервиса и удобство для повседневного использования. Кроме того, почти 70\% опрошенных выделили желание пользоваться этим ресурсом как одну из причин подключения к Интернету [Independent Age 2011].

\section{Повышение доступности публичного Интернета и обучение компьютерной грамотности в сети общественных библиотек}

Еще один из возможных способов стимулирования использования ИКТ - обеспечение равного доступа к информации путем создания общедоступных мест пользования Интернетом. Так, в ряде стран на протяжении многих лет реализуются проекты по повышению доступности ИКТ через сеть публичных библиотек. К примеру, в 2005 г. Правительством Литвы принято постановление о бесплатном пользовании Интернетом в библиотеках [Лауцювене 2007]. Одновременно с этим библиотеки стали центром, обеспечивающим базовые навыки компьютерной грамотности. Опрос пожилых литовцев, чей возраст в среднем составил 60 лет, показал, что 70\% из них овладели базовыми навыками пользования компьютером именно в местных библиотеках [Лауцювене 2007].

Другая масштабная программа по расширению доступности ИКТ для пожилого населения - специальная программа Правительства Великобритании, стартовавшая в 2000 г. За годы реализации программы в стране созданы более 6000 общественных компьютерных центров, расположенных в библиотеках, на улицах, в общественных зданиях, обеспечен свободный доступ к Интернету в общественном транспорте. Около двух миллионов людей ежегодно посещают подобные публичные компьютерные центры, треть из них - инвалиды или лица, имеющие определенные проблемы со здоровьем [Independent Age 2011].

\section{Образовательные услуги}

На овладение навыками компьютерной грамотности лицами старшей возрастной группы направлены и отдельные проекты, реализуемые во многих странах по инициативе как частных компаний, так и общественных организаций, а также силами волонтеров (компьютерные клубы для пожилых, курсы и школы компьютерной грамотности, университеты для пожилых и др.). Многие из реализуемых проектов осуществляются при финансовой поддержке национального правительства.

Удачным примером подобного проекта, инициатором которого стал частный сектор, является масштабная программа по бесплатному обучению компьютерным навыкам людей старше 55 лет «Подключайся, Латвия!», организованная крупнейшим телекоммуникационным предприятием Латвии Lattelecom. В настоящее время инициатива стала проектом национального масштаба и реализуется при поддержке национального правительства. О широкой популярности программы среди пожилых свидетельствуют 
данные о числе ее участников: к середине 2015 г. обучение по этой программе прошли свыше 28000 пожилых латвийцев ${ }^{6}$.

Другой успешный пример - стартовавший в 2004 г. масштабный проект, реализованный американской общественной организацией OATS (“Older Adults Technology Services") в партнерстве более чем с 50 некоммерческими организациями и поддержанный правительством страны. Цель проекта - активизация образа жизни пожилых жителей НьюЙорка через овладение базовыми навыками работы на компьютере [Gardner et. al. 2012]. В течение 8 лет реализации проекта было организовано свыше 10000 уроков, обучение прошли более 6500 пожилых американцев. Анкетирование участников программы показало, что по завершении обучения 98\% опрошенных стали более уверенно пользоваться компьютером. Почти в 2 раза возросла доля пенсионеров, использующих компьютер регулярно. Почти все респонденты отметили, что благодаря обучению расширились их знания о диапазоне возможностей применения ИКТ в повседневной жизни. После завершения программы число пользователей ресурсами сети Интернет возросло почти в 2 раза. Почти все участники продолжили регулярное использование Интернета и спустя шесть месяцев после завершения обучения [Gardner et. al. 2012].

\section{Налоговые льготы при покупке компьютера}

Одним из инструментов, находящихся в распоряжении государства и способных расширить круг лиц старшего возраста, пользующихся ИКТ, могли бы стать налоговые льготы по подоходному налогу для приобретающих компьютеры. Подобная мера способствовала бы как росту общего числа домохозяйств, имеющих домашний компьютер, так и пожилых членов семей, имеющих доступ к нему. Например, в Литве в период с 2004 по 2008 г. действовала программа, согласно которой, покупатель, продекларировавший доходы, мог вернуть до $24 \%$ от стоимости покупки ${ }^{7}$. После введения названной меры в стране существенно выросло число семей, имеющих дома компьютеры. Так, в 2000 г. в стране около 5,3\% населения имели домашние компьютеры, а в 2005 г. домашний компьютер имела почти каждая третья литовская семья: около 36\% городских домохозяйств и около $14 \%$ семей, проживающих на селе [Лауцювене 2007]. Сегодня в России уровень обеспеченности домохозяйств персональными компьютерами достаточно высок, однако по данным Росстата ${ }^{8}$ от 30 до $40 \%$ семей (в зависимости от среднедушевого дохода) попрежнему не имеют компьютера дома, что особенно затрудняет доступ к сети Интернет для пожилых людей, которые обычно менее мобильны, чем молодые.

\section{РЕКОМЕНДАЦИИ ДЛЯ РАЗРАБОТКИ НАЦИОНАЛЬНОЙ ПОЛИТИКИ В ОБЛАСТИ СТАРЕНИЯ}

Анализ политики активного долголетия зарубежных стран показал, что деятельность по

\footnotetext{
${ }^{6} \mathrm{https}: /$ www.lattelecom.lv/ru/o-lattelecom/novosti/proekt-kompyuternyh-kursov-podklyuchajsya-latviyapiesledzies-latvija-v-dalnejshem-budut-realizovyvat-senory

${ }^{7} \mathrm{http}: / /$ www.regnum.ru/news/polit/1105145.html

${ }^{8} \mathrm{http} / /$ www.gks.ru/wps/wcm/connect/rosstat_main/rosstat/ru/statistics/population/level/\#
} 
поддержке пожилых людей стала сегодня неотъемлемой частью социальной политики многих стран мира. Меры, успешно реализованные за рубежом, могут послужить хорошей базой при разработке государственной политики по активизации образа жизни пожилых россиян.

Согласно оценкам, лишь 17\% людей пенсионного возраста в России занимаются физическими упражнениями или спортом [Хоркина, Филиппова 2015]. Вместе с тем в распоряжении государства есть обширный комплекс организационно-просветительских мер и финансовых инструментов, способных оказать позитивное воздействие на физическую активность пожилых людей. Здесь возможны, в частности, специальные руководства и программы физической активности, консультации врачей, телевизионные передачи (для пожилых телевидение - главный источник информации).

Отметим, что в России мероприятия по поддержке физической активности пожилых пока немногочисленны и реализуются в основном общественными или некоммерческими организациями, или частными лицами. По аналогии с другими странами наше государство оказывает финансовую поддержку подобным проектам. Однако проблемой является незначительное количество заявок на финансовую поддержку реализации таких мероприятий. Очевидно, эффективность грантовых механизмов как таковых невысока, требуется целенаправленное информирование всех заинтересованных сторон о наиболее успешных проектах и их результатах для дальнейшего тиражирования лучших практик.

Для более широкого вовлечения российских медиков в кампанию по стимулированию активного образа жизни пожилых необходимо включение в систему повышения квалификации медицинского персонала обучающих программ, раскрывающих основные принципы и особенности проведения консультационной работы с пожилыми людьми.

С целью активизации двигательной активности лиц старшего возраста органы власти отдельных российских регионов уже начали работу по созданию окружающей среды, дружественной пожилым людям, и обустроили специальные пешеходные дорожки и веломаршруты. Обеспечение условий для занятий физкультурой и спортом населения старших возрастов должно стать составляющей социальной политики во всех регионах страны. Росту числа пожилых россиян, занимающихся пешей ходьбой, а также любителей велопрогулок, могло бы способствовать увеличение в регионах числа благоустроенных парков с организованными пунктами проката велосипедов и палок для занятий скандинавской ходьбой.

Современная Россия относится к числу стран с относительно низкой долей пожилых людей, занятых на рынке труда (около 8\% для всей группы лиц старше 65 лет) [Колосницына, Герасименко 2014]. К сожалению, специальная политика, стимулирующая занятость пожилых россиян, сегодня практически отсутствует. Для расширения трудовой активности лиц старшего возраста государство может использовать специальные меры поддержки занятости пожилых от законодательных (антидискриминационных) мер до финансовых, дающих льготы работодателям на создание новых рабочих мест для пожилых работников. Необходимы информационные кампании на государственном уровне; лидером в борьбе с эйджизмом должно стать само государство как важнейший агент «социального 
контракта». Несмотря на то, что российское трудовое законодательство не содержит какихлибо ограничений для пожилых людей, отдельные нормативно-правовые акты допускают ряд возрастных ограничений. Так, Закон о занятости в Российской Федерации ${ }^{9}$ (Статья 5, пункт 2) повторяет, по сути, конституционную формулировку: «обеспечение равных возможностей всем гражданам Российской Федерации независимо от национальности, пола, возраста, социального положения <...> в реализации права на добровольный труд и свободный выбор занятости». Однако среди «граждан, испытывающих трудности в поиске работы» в Законе упомянуты только пожилые люди предпенсионного возраста за 2 года до назначения пенсии. Именно они попадают в зону действия специальных программ занятости, те же, кто хотя бы на год младше или, наоборот, старше и уже стал пенсионером, не могут рассчитывать на специальную государственную поддержку в трудоустройстве. Кроме того, в России действуют возрастные ограничения в отношении работников, занятых на государственной службе.

Российское население пожилого возраста, в отличие от ровесников в других странах, практически не включено в какие-либо виды социальной активности, помимо возможной трудовой деятельности. В этой области действуют в основном НКО, работа которых часто разрозненна и недостаточно обеспечена ресурсами. Крайне низка доля тех, кто хотя бы раз в неделю пользуется Интернетом: по данным выборочного обследования населения по вопросам использования ИКТ, проведенного Росстатом в 2014 г., среди россиян в возрасте 55-59 лет доля активных пользователей Интернета ${ }^{10}$ всего 5,8\%, а в группе 60-72 лет - 4,3\%. Создание возможностей для расширения соџиальной активности пожилых - важное направление государственной политики, и здесь возможны как непосредственное участие государства (в форме создания специальных интернет-клубов для пожилых или возврата части налога при покупке компьютера), так и поддержка государством НКО, работающих в названном направлении. Кроме того, для пожилых людей необходимо обновление знаний, специальные программы повышения квалификации, переобучения (в том числе обучение навыкам работы с ИКТ), инициатором которых должно стать государство. Это позволит повысить их конкурентоспособность на рынке труда, а значит - и доходы, а также создаст дополнительные возможности для других видов социальной активности посредством Интернета. Отметим, что возможность свободного доступа к Интернету в региональных библиотеках, домах культуры, других общественных организациях существует сегодня для пожилых россиян в ряде регионов страны. Однако проблемой является низкая информированность пожилых граждан о месте расположения этих организаций, а также о предоставляемых ими возможностях.

С целью активизации образа жизни пожилых необходимо наладить систематическую работу по тиражированию лучших практик стимулирования всех компонентов активного долголетия. Нужно также отметить необходимость применения современного экономического инструментария для оценки социальной эффективности реализуемых программ с учетом всех социальных издержек и выгод. Представляется, что

\footnotetext{
9 Закон РФ от 19 апреля 1991 г. №1032-1 (ред. от 29.12.2015) «О занятости населения в Российской Федерации».

${ }^{10}$ К активным пользователям относились респонденты, которые использовали интернет не реже 1 раза в неделю. http:/www.gks.ru/wps/wcm/connect/rosstat_main/rosstat/ru/statistics/population/generation/\#
} 
многие из названных выше мер могли бы найти свое отражение в государственной политике активного долголетия.

\section{ЛИТЕРАТУРА}

Вишневский А.Г., Е.М. Андреев (2014). Ближайшие демографические перспективы России. Глава 7 // Население России 2012: двадцатый ежегодный демографический доклад / Отв. ред. А.Г. Вишневский. М.: Изд. дом НИУ ВШЭ: 383-409.

BО3 (2010). Глобальные рекомендации по физической активности для здоровья. URL: http://www.who.int/dietphysicalactivity/factsheet_recommendations/ru/ (дата обращения: 10.01.2016).

Гурвич Е., Ю. Сонина (2012). Микроанализ российской пенсионной системы // Вопросы экономики. 2: 27-51.

Демографический ежегодник России (2015). Демографический ежегодник России. Статистический сборник. М.: Росстат.

Колосницына М.Г., М.А. Герасименко (2014). Экономическая активность в пожилом возрасте и политика государства // Вопросы государственного и муниципального управления. 4: 47-68.

Лауцювене Б. (2007). Интернет и основы компьютерной грамотности для пожилых людей в библиотеке // Научные и технические библиотеки. 3: 74-77.

Малева Т.М., К.В. Юдаева (2013). Реформа пенсионной системы. Глава 6 // Стратегия2020: Новая модель роста - новая социальная политика. Итоговый доклад о результатах экспертной работы по актуальным проблемам социально-экономической стратегии России на период до 2020 года / В.А. Мау, Я.И. Кузьминов (ред.). М.: Дело: 197-228. URL: https://www.hse.ru/pubs/share/direct/document/99110182 ( дата обращения: 08.01.2016).

Румянцева Е. (2013). Возможности активизации роли пожилых людей в обществе // Государственная служба. 1: 49-51.

Сабитова Л.М., Г.А. Миннигалеева, К.В. Дёмина (2011). Роль государственных и негосударственных организаций для обеспечения реализации социального потенциала пожилых в России // Доклад на XII Международной научной конференции по проблемам развития экономики и общества, 5-7 апреля. URL: http://regconf.hse.ru/uploads/f807e831276b0e42ca11687957f68470b714fec5.doc (дата обращения: 30.01.2016).

Синявская О. (2010). Российская пенсионная реформа: куда идти дальше? // SPERO. 13: $187-210$.

Сонина Ю.В., М.Г. Колосницына (2015). Пенсионеры на российском рынке труда: тенденции экономической активности людей пенсионного возраста // Демографическое обозрение. 2: 37-53.

Хоркина Н.А., А.В. Филиппова (2015). Физическая активность пожилых людей как объект управляющего воздействия государства // Вопросы государственного и муниципального управления. 2: 197-222. 
A literature review... (2011). A literature review of evidence on physical activity for older people and a review of existing physical activity guidelines for older people. University of Western Sydney, New Zeland Guidelines Group. 302 p.

AARP (American association of retired persons) (2007). Community-wide campaign to promote physical activity among midlife and older adults: lessons learned from AARP's active for life ${ }^{\mathrm{TM}}$ campaign and a synopsis of evidence-based interventions. URL:

http://assets.aarp.org/www.aarp.org_/articles/health/active_for_life_chapter_01.pdf (дата обращения: 08.01.2016).

Blöndal S., S. Scarpetta (1998). The retirement decision in OECD countries // OECD Economics department working papers. ECO/WKR(98)15. 202. URL: http://www.oecd.org/eco/labour/1866098.pdf (дата обращения: 10.01.2016 ).

Bull F.C., K. Jamrozik (1998). Advice on exercise from a family physician can help sedentary patients to become active // American journal of preventive medicine. 15(2): 85-94.

Burniaux J-M., R. Duval R, F. Jaumotte (2003). Coping with ageing: a dynamic approach to quantify the impact of alternative policy options on future labour supply in OECD countries // OECD Economics department working papers. ECO/WKP(2003)25. 371. URL: http://www.oecd.org/officialdocuments/publicdisplaydocumentpdf/?doclanguage $=$ en \& cote $=\mathrm{e}$ co/wkp\%282003\%2925 (дата обращения: 10.01.2016).

California Agencies... (2007). California agencies promote strength-training programs for older adults. URL: http://www.rwjf.org/reports/grr/039593.html (дата обращения: 08.01.2016).

Chansarn S. (2012). Active ageing of elderly people and its determinants: empirical evidence from Thailand // Asia-pacific social science review. 12(1): 1-18.

Duval R. (2003). The retirement effects of old-age pension and early retirement schemes in OECD countries // OECD Economics department working papers. ECO/WKP(2003)24. 370. URL: http://www.oecd.org/officialdocuments/publicdisplaydocumentpdf/?cote=ECO/WKP(2003)2 4\&docLanguage=En (дата обращения: 10.01.2016 ).

Finch H. (1997). Physical activity 'at our age'. Qualitative research among people over the age of 50. London: Health education authority. 83 p.

Friedberg L. (2007). The recent trend towards later retirement. Boston: Center for retirement research at Boston college.

Ganzglass E. (2014). Scaling "Stackable credentials" implications for implementation and policy. Washington, DC: Center for law and social policy. $23 \mathrm{p}$.

Gardner P., T. Kamber, J. Netherland (2012). Getting turned on: using ICT training to promote active ageing in New York City // The journal of community informatics. 8(1): 1-16.

Go for life... (2014). Go for life grant scheme. URL: http://ageandopportunity.ie/what-wedo/physical-activity-sport/go-for-life-grant-scheme (дата обращения: 08.01.2016).

Gruber J., D. Wise (eds.) (2004). Social security and retirement around the world: microestimation. Chicago and London: University of Chicago Press. 737 p. URL: http://www.nber.org/chapters/c10697.pdf (дата обращения: 10.01.2016).

HelpAge International (2015). Global agewatch index 2015: insight report. URL: http://reports.helpage.org/global-agewatch-index-2015-insight-report.pdf (дата обращения: 31.01.2016). 
Hirvensalo M., T. Lintunen, T. Rantanen (1998). Physical exercise in old age: an eight-year follow-up study on involvement, motives and obstacles among persons age 65-84// Journal of aging and physical activity. 6(2): 157-168.

Independent Age (2011). Older people, technology and community: the potential of technology to help older people renew or develop social contacts and to actively engage in their communities. Calouste Gulbenkian foundation. 37 p. URL:

http://www.cisco.com/c/dam/en_us/about/ac79/docs/wp/ps/Report.pdf (дата обращения: 20.01.2016).

Jacobson L., R. LaLonde, D. Sullivan (2003). Should we teach old dogs new tricks? The impact of community college retraining on older displaced workers. Chicago, IL: Federal Reserve Bank of Chicago. 85 p.

Karvinen E., P. Kalmari, H. Starck, A. Urtamo, M. Säpyskä-Nordberg, U. Salminen, A. Havas, V. Farin (2014). Strength in old age - health exercise programme for older adults (20052015). The Age institute. URL: http://www.ikainstituutti.fi/binary/file/-/id/3/fid/402 (дата обращения: 08.04.2016).

Nicholson L. (2004). Older people, sport and physical activity: a review of key issues. Research report. 96. Edinburgh. URL:

http://www.sportscotland.org.uk/documents/research_reports/older_people_digest_final.pdf (дата обращения: 08.04.2016).

OECD (1999). Recent labour market developments and prospects: special focus on the quality of part-time jobs // OECD Employment outlook. Paris: OECD: 14-46.

OECD (2004). Ageing and employment policies: United Kingdom. OECD publishing. 152 p.

OECD (2005a). Ageing and employment policies: Germany. OECD publishing. 168 p.

OECD (2005b). Ageing and employment policies: Netherlands. OECD publishing. 145 p.

OECD (2006). Ageing and employment policies: live longer, work longer. OECD publishing. $146 \mathrm{p}$.

Ruhm C. (1990). Bridge jobs and partial retirement // Journal of labor economics. 8(4): 482-501.

Schoppe S., A. Bauman, F. Bull (2004). International review of national physical activity policy: a literature review. CPAH Report. 04-0002. Sydney, Australia.76 p.

Stathi A., J. McKenna, K.R. Fox (2003). The experiences of older people participating in exercise referral schemes // Journal of the royal society for the promotion of health. 124(1): $18-23$.

Schils T. (2008). Early retirement in Germany, the Netherlands and the United Kingdom: a longitudinal analysis of individual factors and institutional regimes // European sociological review. 24(3): 315-329.

Van Horn C.E., K. Krepcio, M. Heidkamp (2015). Improving education and training for older workers. Research report, American association of retired persons. $54 \mathrm{p}$.

WHO (2002). Active aging: a policy framework. Geneva, Switzeland. URL: http://whqlibdoc.who.int/hq/2002/who_nmh_nph_02.8.pdf (дата обращения: 30.06.2016).

Zaidi A., K. Gasior, M. Hofmarcher, O. Lelkes, B. Marin, R. Rodrigues, A. Schmidt, P. Vanhuysse, E. Zolyomi (2013). Active ageing index 2012. Concept, methodology and final results. Project: Active Ageing Index (AAI). UNECE Grant ECE/GC/2012/003. 68 p. 
Zasimova L., M. Sheluntcova (2014). Measuring active aging for government policy planning: a case of Russia // Working papers by NRU Higher school of economics. Series PA "Public administration". WP BRP 11/PA/2014. 11. 


\title{
PUBLIC POLICIES OF ACTIVE AGEING: EVIDENCE FROM THE WORLD EXPERIENCE
}

\author{
MARINA KOLOSNITSYNA, NATALIYA KHORKINA
}

\begin{abstract}
Population aging is a trend characteristic today for the majority of countries, and Russia is not an exception. The number and proportion of older persons is growing and most governments enact "active ageing" policies and programmes that enhance the health and participation of older people. Many special international documents on these issues were adopted, a number of countries have today separate governmental bodies responsible for policies towards older people. States develop national strategies, support private initiatives and NGO working with elders. In Russia, public policy aimed at active ageing still lacks clear goals and structure. This paper analyses international experience of active ageing policies. Using existing efficiency estimates, we reveal those policy measures that have proved to be most effective and could be applied in our country. In our review we pay special attention at the countries-leaders of the world ratings of older people life quality. During many years those states have been applying different instruments of social policies towards seniors at the country level, as well as at the regional and local levels. They intentionally monitor all the programmes applied and evaluate the mechanisms in use. According to the concept of active ageing suggested by the World Health Organization, we analyze the main components of active ageing such as physical, social and labor activities. The analysis of international practices let us reveal the most efficient instruments of active ageing policy (financial, educational, organizational, informational instruments). In conclusion, we give recommendations for national policy of active ageing to be applied in Russia.
\end{abstract}

Key words: active ageing, older people, physical activities, labour activities, social activities, public social policy.

\begin{abstract}
MARINA G. Kolosnitsyna (mkolosnitsyna@hse.ru), NATIONAL RESEARCH University Higher SchoOl OF ECONOMICS, RUSSIA.

Nataliya A. Khorkina, National Research University Higher School of Economics, Russia.

THE RESULTS OF THE PROJECT " SOCIAL PROTECTION: TARGET GROUPS AND PRIORITIES", CARRIED OUT WITHIN THE FRAMEWORK OF THE BASIC RESEARCH PROGRAM AT THE NATIONAL RESEARCH UNIVERSITY HIGHER SCHOOL OF ECONOMICS (HSE) IN 2016, ARE PRESENTED IN THIS PAPER.
\end{abstract}

DATE RECEIVED: OCTOBER 2016.

\section{REFERENCES}

A literature review... (2011). A literature review of evidence on physical activity for older people and a review of existing physical activity guidelines for older people. University of Western Sydney, New Zeland Guidelines Group. 302 p.

AARP (American association of retired persons) (2007). Community-wide campaign to promote physical activity among midlife and older adults: lessons learned from AARP's active for life ${ }^{\mathrm{TM}}$ campaign and a synopsis of evidence-based interventions. URL: http://assets.aarp.org/www.aarp.org_/articles/health/active_for_life_chapter_01.pdf (accessed: 08.01.2016).

Blöndal S., S. Scarpetta (1998). The retirement decision in OECD countries // OECD Economics department working papers. ECO/WKR(98)15. 202. URL: http://www.oecd.org/eco/labour/1866098.pdf (accessed: 10.01.2016).

Bull F.C., K. Jamrozik (1998). Advice on exercise from a family physician can help sedentary patients to become active // American journal of preventive medicine. 15(2): 85-94. 
Burniaux J-M., R. Duval R, F. Jaumotte (2003). Coping with ageing: a dynamic approach to quantify the impact of alternative policy options on future labour supply in OECD countries // OECD Economics department working papers. ECO/WKP(2003)25. 371. URL: http://www.oecd.org/officialdocuments/publicdisplaydocumentpdf/?doclanguage $=$ en \&cote $=\mathrm{e}$ co/wkp\%282003\%2925 (accessed: 10.01.2016).

California Agencies... (2007). California agencies promote strength-training programs for older adults. URL: http://www.rwjf.org/reports/grr/039593.html (accessed: 08.01.2016).

Chansarn S. (2012). Active ageing of elderly people and its determinants: empirical evidence from Thailand // Asia-pacific social science review. 12(1): 1-18.

Demograficheskiy ezhegodnik Rossii [The demographic yearbook of Russia] (2015). Statisticheskiy sbornik [Statistical handbook]. Moscow: Rosstat.

Duval R. (2003). The retirement effects of old-age pension and early retirement schemes in OECD countries // OECD Economics department working papers. ECO/WKP(2003)24. 370. URL: http://www.oecd.org/officialdocuments/publicdisplaydocumentpdf/?cote=ECO/WKP(2003)2 4\&docLanguage $=$ En (accessed: 10.01.2016).

Finch H. (1997). Physical activity 'at our age'. Qualitative research among people over the age of 50. London: Health education authority. 83 p.

Friedberg L. (2007). The recent trend towards later retirement. Boston: Center for retirement research at Boston college.

Ganzglass E. (2014). Scaling "Stackable credentials" implications for implementation and policy. Washington, DC: Center for law and social policy. $23 \mathrm{p}$.

Gardner P., T. Kamber, J. Netherland (2012). Getting turned on: using ICT training to promote active ageing in New York City // The journal of community informatics. 8(1): 1-16.

Go for life... (2014). Go for life grant scheme. URL: http://ageandopportunity.ie/what-wedo/physical-activity-sport/go-for-life-grant-scheme (accessed: 08.01.2016).

Gruber J., D. Wise (eds.) (2004). Social security and retirement around the world: microestimation. Chicago and London: University of Chicago Press. 737 p. URL: http://www.nber.org/chapters/c10697.pdf (accessed: 10.01.2016).

Gurvich Y., Y. Sonina (2012). Mikroanaliz rossiyskoy pensionnoy sistemy [Microanalysis of Russian pension system] // Voprosy ekonomiki [Voprosy ekonomiki]. 2: 27-51.

HelpAge International (2015). Global agewatch index 2015: insight report. URL: http://reports.helpage.org/global-agewatch-index-2015-insight-report.pdf (accessed: 31.01.2016).

Hirvensalo M., T. Lintunen, T. Rantanen (1998). Physical exercise in old age: an eight-year follow-up study on involvement, motives and obstacles among persons age 65-84 // Journal of aging and physical activity. 6(2): 157-168.

Independent Age (2011). Older people, technology and community: the potential of technology to help older people renew or develop social contacts and to actively engage in their communities. Calouste Gulbenkian foundation. 37 p. URL: http://www.cisco.com/c/dam/en_us/about/ac79/docs/wp/ps/Report.pdf (accessed: 20.01.2016). 
Jacobson L., R. LaLonde, D. Sullivan (2003). Should we teach old dogs new tricks? The impact of community college retraining on older displaced workers. Chicago, IL: Federal Reserve Bank of Chicago. 85 p.

Karvinen E., P. Kalmari, H. Starck, A. Urtamo, M. Säpyskä-Nordberg, U. Salminen, A. Havas, V. Farin (2014). Strength in old age - health exercise programme for older adults (20052015). The Age institute. URL: http://www.ikainstituutti.fi/binary/file/-/id/3/fid/402 (accessed: 08.04.2016).

Khorkina N.A., A.V. Filippova (2015). Fizicheskaya aktivnost' pozhilykh lyudey kak ob"ekt upravlyayushchego vozdeystviya gosudarstva [Physical activity of elderly people as a public policy object] // Voprosy gosudarstvennogo i munitsipal'nogo upravleniya [Public administration issues]. 2: 197-222.

Kolosnitsyna M.G., M.A. Gerasimenko (2014). Ekonomicheskaya aktivnost' v pozhilomvozraste i politika gosudarstva [Labour force participation of elderly and public policy] // Voprosy gosudarstvennogo i munitsipal'nogo upravleniya [Public administration issues]. 4: 47-68.

Lautsyuvene B. (2007). Internet i osnovy komp'yuternoy gramotnosti dlya pozhilykh lyudey v biblioteke [Internet and basics of IT-literacy in a library for elder people] // Nauchnye i tekhnicheskie biblioteki [Scientific and technical libraries]. 3: 74-77.

Maleva T.M., K.V. Yudaeva (2013). Reforma pensionnoy sistemy. Glava 6 [Pension system's reform. Chapter 6] // Strategiya-2020: Novaya model' rosta — novaya sotsial'naya politika. Itogovyy doklad o rezul'tatakh ekspertnoy raboty po aktual'nym problemam sotsial'noekonomicheskoy strategii Rossii na period do 2020 goda [New model of growth - new social policy. Final experts' report on urgent problems of Russian socio-economic strategy for 2020] / V.A. Mau, Ya.I. Kuz'minov (eds.). Moscow: Delo: 197-228. URL: https://www.hse.ru/pubs/share/direct/document/99110182 (accessed: 08.01.2016).

Nicholson L. (2004). Older people, sport and physical activity: a review of key issues. Research report. 96. Edinburgh. URL:

http://www.sportscotland.org.uk/documents/research_reports/older_people_digest_final.pdf (accessed: 08.04.2016).

OECD (1999). Recent labour market developments and prospects: special focus on the quality of part-time jobs // OECD Employment outlook. Paris: OECD: 14-46.

OECD (2004). Ageing and employment policies: United Kingdom. OECD publishing. 152 p.

OECD (2005a). Ageing and employment policies: Germany. OECD publishing. 168 p.

OECD (2005b). Ageing and employment policies: Netherlands. OECD publishing. 145 p.

OECD (2006). Ageing and employment policies: live longer, work longer. OECD publishing. $146 \mathrm{p}$.

Ruhm C. (1990). Bridge jobs and partial retirement // Journal of labor economics. 8(4): 482-501.

Rumyantseva E. (2013). Vozmozhnosti aktivizatsii roli pozhilykh lyudey v obshchestve [Older people's role in society: possibilities for activization] // Gosudarstvennaya sluzhba [Public service]. 1: 49-51.

Sabitova L.M., Minnigaleeva G.A., Demina K.V. (2011). Rol' gosudarstvennykh i negosudarstvennykh organizatsiy dlya obespecheniya realizatsii sotsial'nogo potentsiala pozhilykh v Rossii [Russian state organizations and NGO in realization of older people potential]. Doklad na XII Mezhdunarodnoy nauchnoy konferentsii po problemam razvitiya ekonomiki i obshchestva [The report of the XII International academic conference on economic and social development], 5-7 April. Available at: 
http://regconf.hse.ru/uploads/f807e831276b0e42ca11687957f68470b714fec5.doc (accessed: 30 January 2016).

Schoppe S., A. Bauman, F. Bull (2004). International review of national physical activity policy: a literature review. CPAH Report. 04-0002. Sydney, Australia.76 p.

Sinyavskaya O. (2010). Rossijskaya pensionnaya reforma: kuda idti dal'she? [The Russian pension reform: what are the future challenges?] // SPERO. 13: 187-210.

Sonina Y., M. Kolosnitsyna (2015). Pensionery na rossiyskom rynke truda: tendentsii ekonomicheskoy aktivnosti lyudey pensionnogo vozrasta [Pensioners on the Russian labour market: trends of economic activity in pension age] // Demograficheskoe obozrenie [Demographic review]. 2: 37-53.

Stathi A., J. McKenna, K.R. Fox (2003). The experiences of older people participating in exercise referral schemes // Journal of the royal society for the promotion of health. 124(1): $18-23$.

Schils T. (2008). Early retirement in Germany, the Netherlands and the United Kingdom: a longitudinal analysis of individual factors and institutional regimes // European sociological review. 24(3): 315-329.

Van Horn C.E., K. Krepcio, M. Heidkamp (2015). Improving education and training for older workers. Research report, American association of retired persons. 54 p.

Vishnevsky A.G., E.M. Andreev (2014). Blizhayshie demograficheskie perspektivy Rossii. Glava 7 [Nearest demographic perspectives of Russia. Chapter 7] // Naselenie Rossii 2012: dvadtsatyy ezhegodnyy demograficheskiy doklad [Population of Russia 2012: 20th annual demographic report] / A.G. Vishnevsky, ed. Moskva: HSE: 383-409.

VOZ (2010). Global'nye rekomendatsii po fizicheskoy aktivnosti dlya zdorov'ya [Global recommendations on physical activity for health]. URL:

http://www.who.int/dietphysicalactivity/factsheet_recommendations/ru/ (accessed: 10.01.2016).

WHO (2002). Active aging: a policy framework. Geneva, Switzeland. URL: http://whqlibdoc.who.int/hq/2002/who_nmh_nph_02.8.pdf (accessed: 30.06.2016).

Zaidi A., K. Gasior, M. Hofmarcher, O. Lelkes, B. Marin, R. Rodrigues, A. Schmidt, P. Vanhuysse, E. Zolyomi (2013). Active ageing index 2012. Concept, methodology and final results. Project: Active Ageing Index (AAI). UNECE Grant ECE/GC/2012/003. 68 p.

Zasimova L., M. Sheluntcova (2014). Measuring active aging for government policy planning: a case of Russia // Working papers by NRU Higher school of economics. Series PA "Public administration". WP BRP 11/PA/2014. 11. 